\title{
Comparative Study on Life of High-speed Bearings at Ultimate Low Tempera- ture
}

Weihua Zhao(0000-0001-9372-3782) $)^{1,2,3}$,Qinghou Chen(0000-0002-3812-2092) 1,2,3, Cong Ma(0000-0002-2619198X) ${ }^{1,2,3}$, Danfeng Yang(0000-0002-0753-2785) ${ }^{1,2,3}$, Kenan Yang(0000-0002-2078-4637) ${ }^{1,2,3}$, Lai Hu(0000-00029660-9536) ${ }^{4}$

${ }^{1}$ Luoyang Bearing Science \&Technology Co., Ltd., Luoyang 471039, China.

${ }^{2}$ Henan Key Laboratory of High Performance Bearing Technology, Luoyang 471039, China.

${ }^{3}$ Strategic Alliance for Technology Innovation in Rolling Bearing Industry, Luoyang 471039, China.

${ }^{4}$ School of Mechanical Engineering, Xi'an Jiaotong University, 28 Xianning Road, Xi'an, Shaanxi 710049, P.R. China, E-mail: Lai Hu: Laifinial@163.com

Aiming to improve the working life of high-speed rail bearings, this paper puts forward a comparative study on different types of high-speed rail bearings at extreme low temperature. The model of bearing life is established. In the whole test process, it is found that the change trends of bearing temperature, environment temperature and torque are basically the same. In the equilibrium temperature relationship between SKF and $\mathrm{ZH}$ bearings, the temperature divergence of SKF bearings finally appears. In the $\mathrm{ZH}$ bearings, bearing 4 appears irregular sharp drop at the end. However, the temperature changes of the two brands of bearings are between $-150^{\circ} \mathrm{C}$ and $-170^{\circ} \mathrm{C}$. And the friction coefficient is proportional to the ratio of torque. In the comparison of grinding amount, the wear amount of $\mathrm{ZH}$ bearings is far lower than that of SKF bearings, with a difference of about $0.5 \mathrm{~mm}$. This shows that the production process and surface treatment methods of the two types bearing are completely different.

Keywords: High-speed rail bearing, Life span, Temperature, Wear, Torque

\section{Introduction}

Bearing is a high-speed rotating component, and its working conditions are very complex. Generally, bearings need to work at high speed and for a long time under complex stress states and high stress values such as tension, compression, bending, shear and alternating. The parts with low fatigue strength on the surface of the bearing ring first produce fatigue cracks, and finally form fatigue spalling, which makes the bearing damaged and invalid. In the final analysis, it is mainly to improve the service life of high-speed rail bearings. In this field, some authors have also put forward some research methods. For example, Feng J et al. [1] proposed to combine Hertz theory and elastic contact stress analysis theory with finite element analysis method to discuss the stress distribution between bearing rollers and raceways of a certain type of high-speed railway. Y Huang et al. [2] proposed an improved scale space VMD, which uses scale space representation to understand the analysis signal a priori and find out the parameters, thus estimating the number of IMF in advance and optimizing other parameters of VMD. C $\mathrm{Ma}$ et al. [3] established a calculation method for bearing fatigue life, and studied the effects of inclusion size, contact surface depth and elastic modulus on bearing fatigue life. Gergely M [4], S. Sjostrom [5] and R. Schroder [6] all simulated the process conditions and product dimensions during the heat treatment process, and studied the correlation affecting the bearing life. Tudose $\mathrm{C}$ et al. [7] studied the influence of reasonable calculation of shaft bearing reaction on bearing life prediction. V. V. et al. [8] analyzed the life of bearings during drilling, milling and boring on the basis of the newly derived calculation method of bearing life. Reference [9-11] also studies the life of bearings.

Therefore, it is proposed to study the life of highspeed rail bearings. Four sets of bearings of two different brands (SFK and $\mathrm{ZH}$ ) were selected as research carriers. Taking the extreme low temperature $\left(-160^{\circ} \mathrm{C}\right)$ as the test ambient temperature, the change trend of total temperature, the relationship between bearing equilibrium temperature, the relationship between torque and wear coefficient, and the change of bearing torque and wear amount of two brands of bearings are analyzed.

\section{Establishment of bearing life model.}

At present, in engineering applications, bearing manufacturers generally accept the improved ISO standard based on Lundberg-Palmgren bearing life theory. ISO standard needs to calculate the equivalent dynamic load and rated static load of bearings. According to the theory of bearing rated life, the rated life of ball bearings is: 


$$
L_{10}=\left(L_{i}^{-\varepsilon}+L_{e}^{-\varepsilon}\right)^{-1 / \varepsilon}
$$

The rated life of the inner raceway is:

$$
L_{i}=\left(\frac{Q_{c \mu j}}{Q_{\mu j}}\right)^{3}
$$

The rated life of the outer raceway is:

$$
L_{e}=\left(\frac{Q_{c v j}}{Q_{v j}}\right)^{3}
$$

$Q_{c \mu j}, Q_{c j}$ are the rated static load of the ring.

$$
Q_{c}=98.1\left(\frac{f}{2 f-1}\right)^{0.41} \frac{(1 \mp \gamma)^{1.39}}{(1 \pm \gamma)^{\frac{1}{3}}}\left(\frac{\gamma}{\cos \alpha}\right)^{0.3} D_{b}^{1.8} Z^{-\frac{1}{3}}
$$

Where; $\mp$ is the rated dynamic load of the inner and outer rings.

The equivalent dynamic load $Q_{\mu i}$ of the rotating inner raceway is:

$$
Q_{\mu i}=\left(\frac{1}{Z} \sum_{j=1}^{j=Z} Q_{j}^{\frac{10}{3}}\right)^{0.3}
$$

The equivalent dynamic load $Q_{v i}$ of the non-rotating outer raceway is:
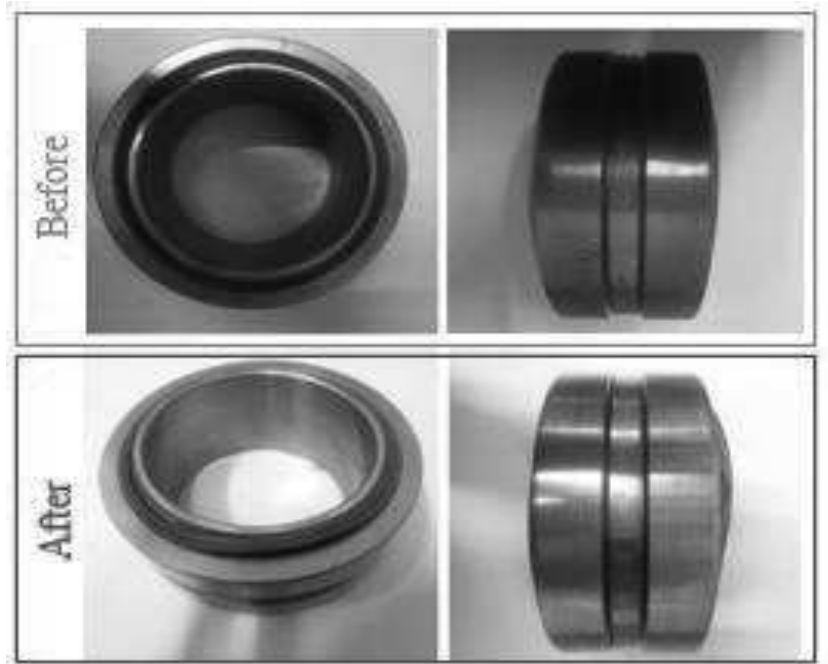

a) Bearing 1

$$
Q_{v i}=\left(\frac{1}{Z} \sum_{j=1}^{j=Z} Q_{j}^{\frac{10}{3}}\right)^{0.3}
$$

Where; $J$ is the number of bearing balls; $Z$ is the total number of balls.

\section{Test of bearings of different brands and models.}

Based on the above theory, two brands (GE-90SKF and GE-90-ZH) are selected, and four sets of bearings are selected for each brand. The test mainly obtains the service life (swing test times not less than 30000 times) and life evolution law of bearing samples at low temperature $\left(-160^{\circ} \mathrm{C}\right)$. In the test of two brands of bearings, the same load of $92.4 \mathrm{KN}$ and the rotating speed of $1 \mathrm{r} / \mathrm{min}$ were applied.

\subsection{SKF bearings test}

Four sets of bearings in GE-90-SKF samples were selected for research. Fig. 1 shows the comparison results of two sets of tests in the sample piece before and after the test. The test results are shown in Figs. 2-6.
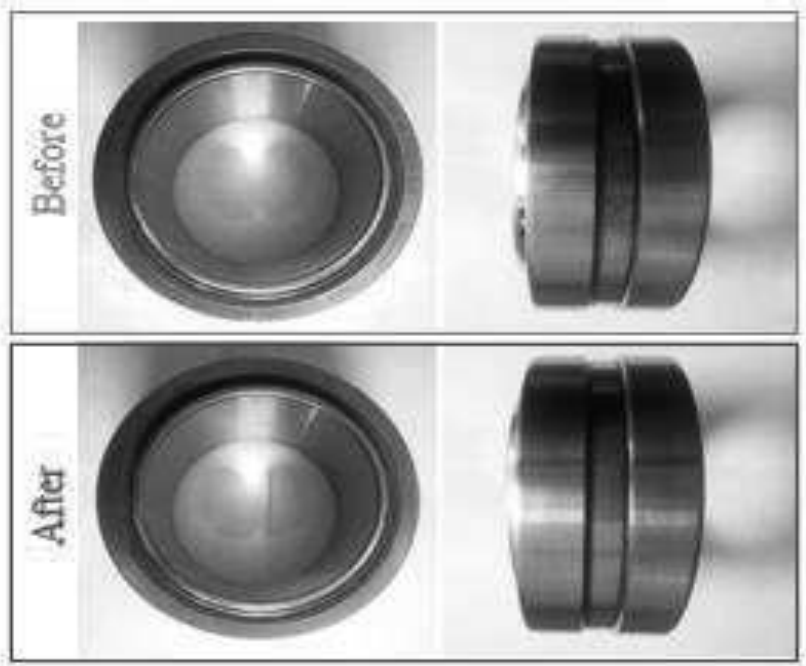

b) Bearing 2

Fig. 1 Comparison diagram of SKF bearings before and after test.

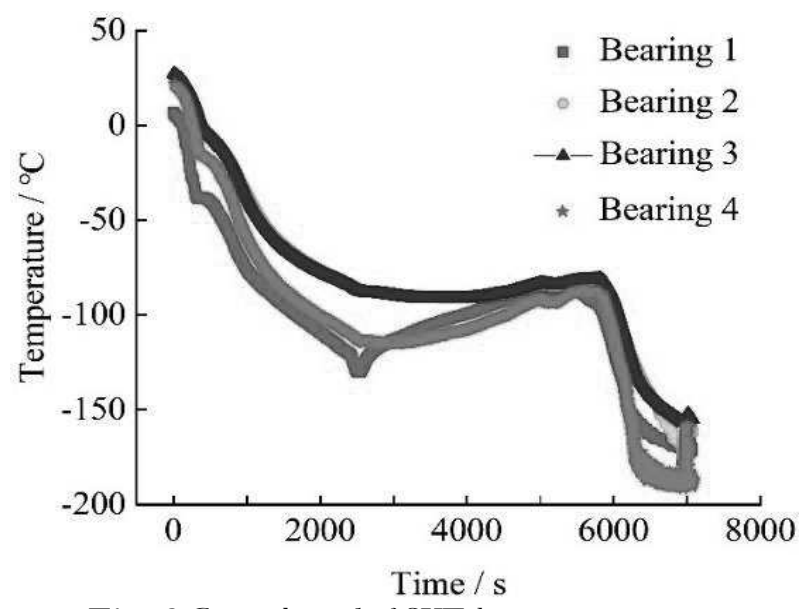

Fig. 2 General trend of SKF bearings temperature

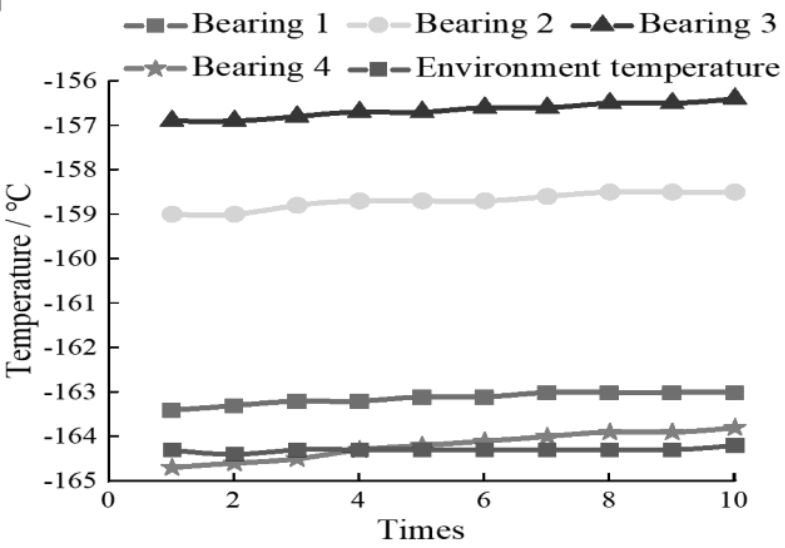

Fig. 3 SKF bearings section temperature and environment temperature 


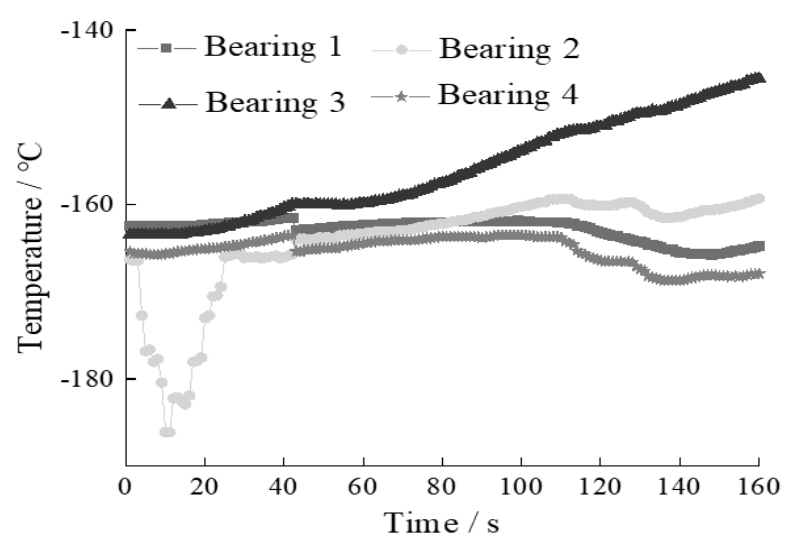

Fig. 4 SKF Bearings equilibrium temperature relationship

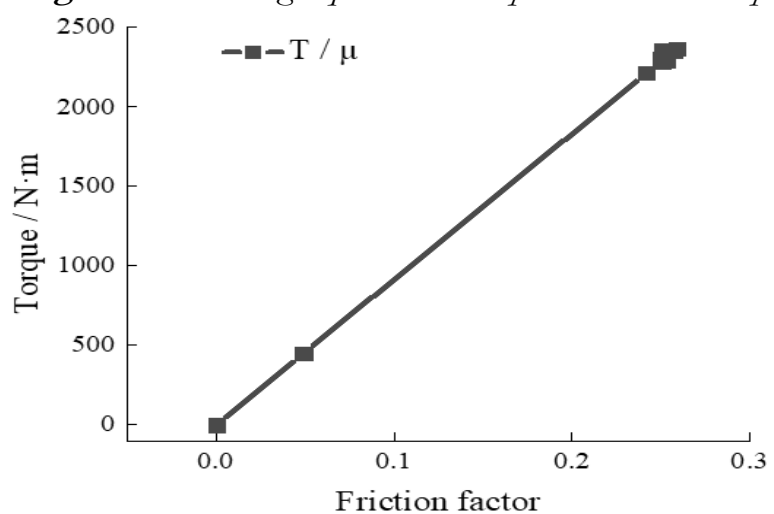

Fig. 5 Comparative relationship between test torque and friction coefficient of SKF bearings

According to the appearance analysis of the bearing before and after the test in Fig. 1, there is no obvious fracture or damage. From the overall temperature change in Fig. 2, the temperature change trends of the four sets of bearings are basically the same. Finally, it reaches the preset temperature $\left(-160^{\circ} \mathrm{C}\right)$. In addition, it should be noted that the sudden change in temperature was caused by changing the liquid nitrogen tank, which did not affect the overall test process.
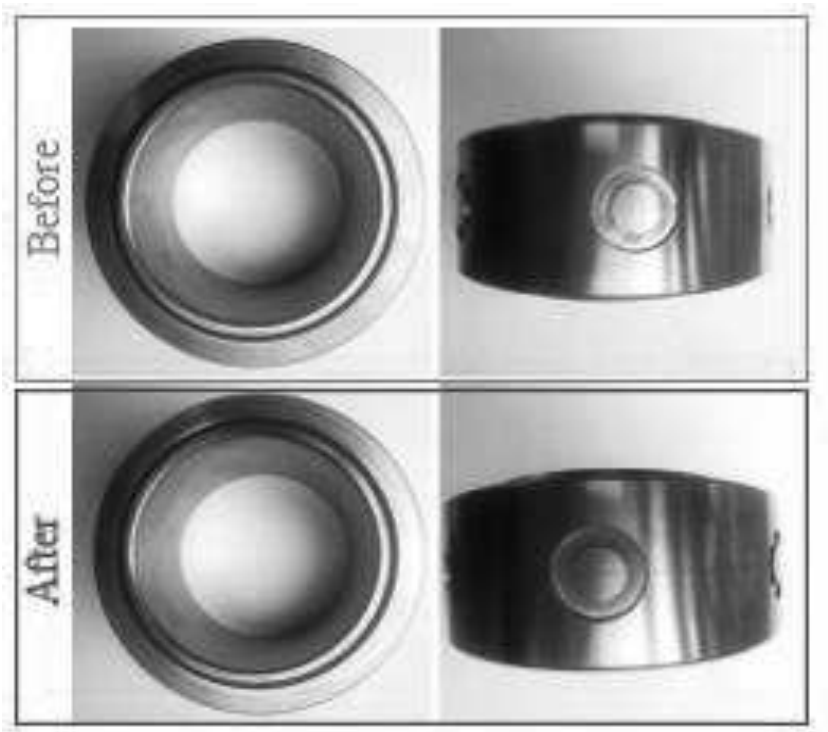

From the analysis of the ambient temperature relationship in Fig. 5, no matter whether the temperature of the four sets of bearings changes or not, the ambient temperature is always in a balanced state. This shows that the stability of the test equipment is very good. Figs. 4-6 will be comprehensively analyzed in the fourth part.

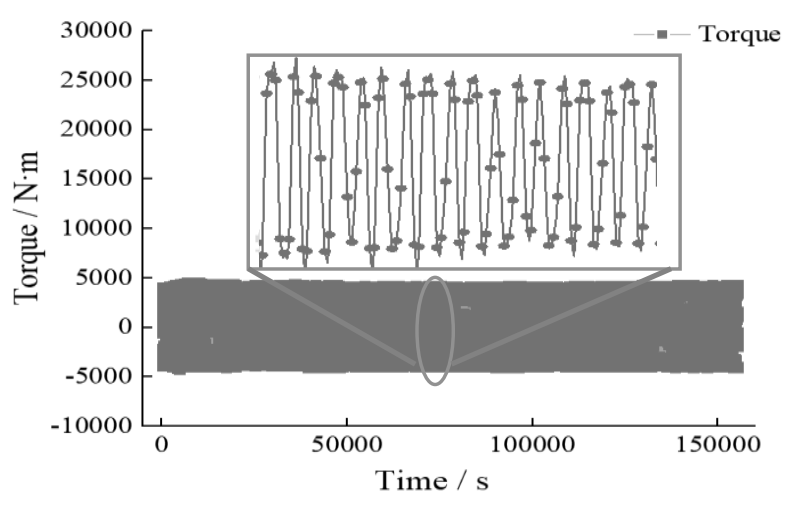

Fig. 6 SKF bearings torque

\section{2 $\mathrm{ZH}$ bearings test.}

Apply the same parameters to bearing GE-90-ZH according to section 3.1. The test mainly obtains the service life (swing test times not less than 30000 times) and life evolution law of bearing samples at low temperature $\left(-160^{\circ} \mathrm{C}\right)$. Bearing GE-90-ZH, load $92.4 \mathrm{KN}$, rotating speed $1 \mathrm{r} / \mathrm{min}$ at $-160^{\circ} \mathrm{C}$. Fig. 7 shows 2 sets of bearings from 4 sets of samples. Because in the analysis results of GE-90-ZH bearing, the overall temperature trend of bearing and the comparison of ambient temperature are basically consistent with the analysis results in section 3.1. Therefore, the GE-90-ZH bearing analysis results only list the $\mathrm{ZH}$ bearings equilibrium temperature relationship (Fig. 8), the comparison relationship between the $\mathrm{ZH}$ bearings test torque and the friction coefficient (Fig. 9), and the ZH bearings torque (Fig. 10).

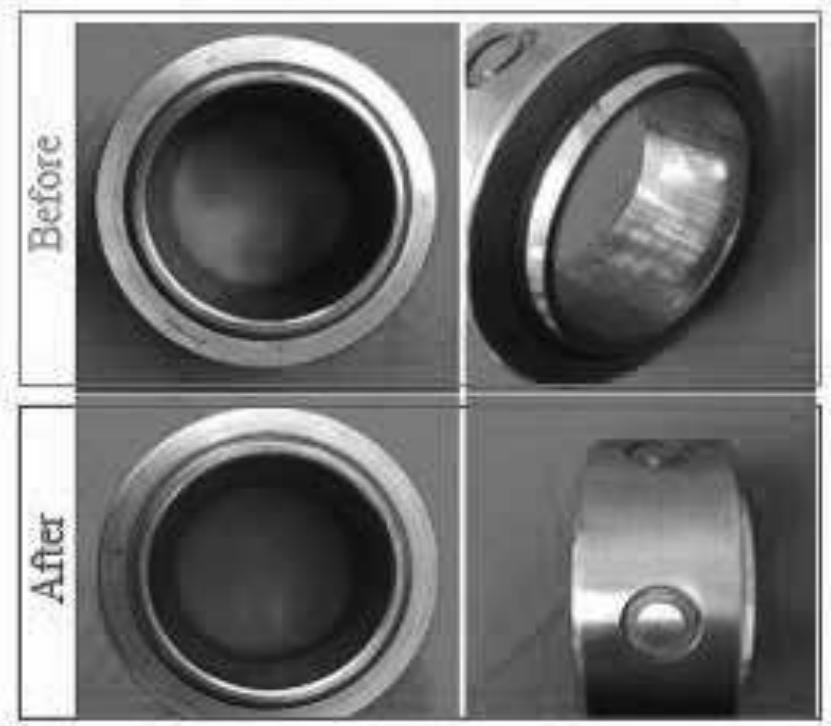

Fig. 7 Comparison diagram of $Z H$ bearings before and after test. 


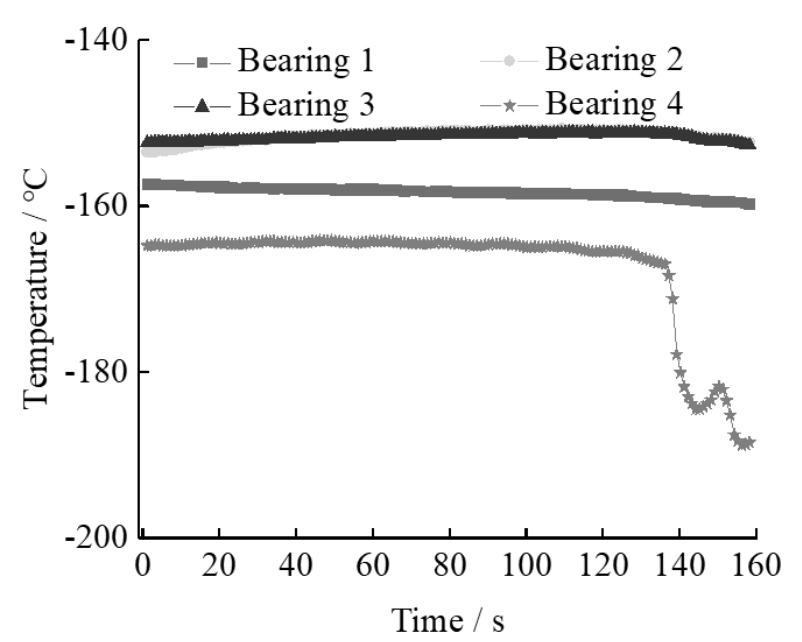

Fig. $8 \mathrm{ZH}$ bearings equilibrium temperature relationship.

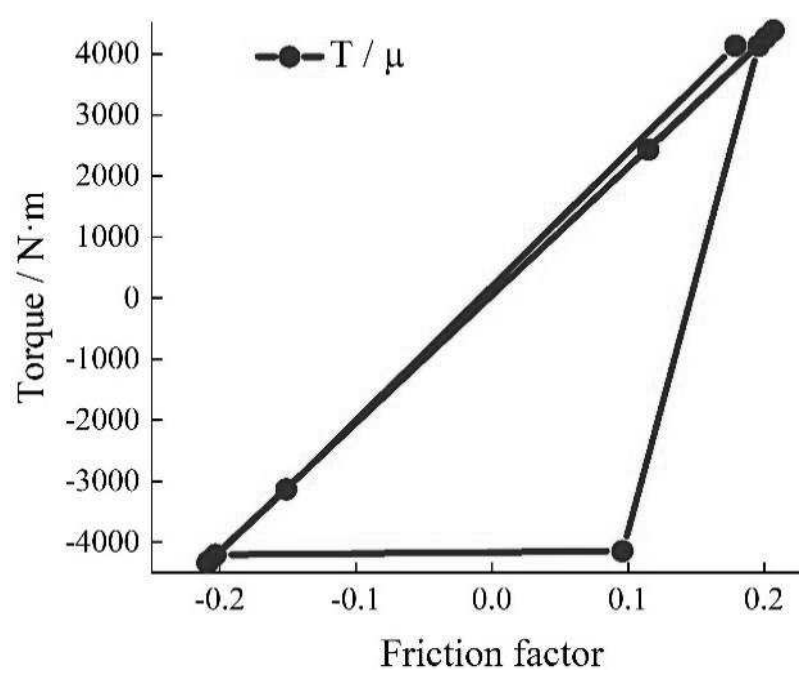

Fig. 9 Contrast relationship between test torque and friction coefficient of $\mathrm{ZH}$ bearings

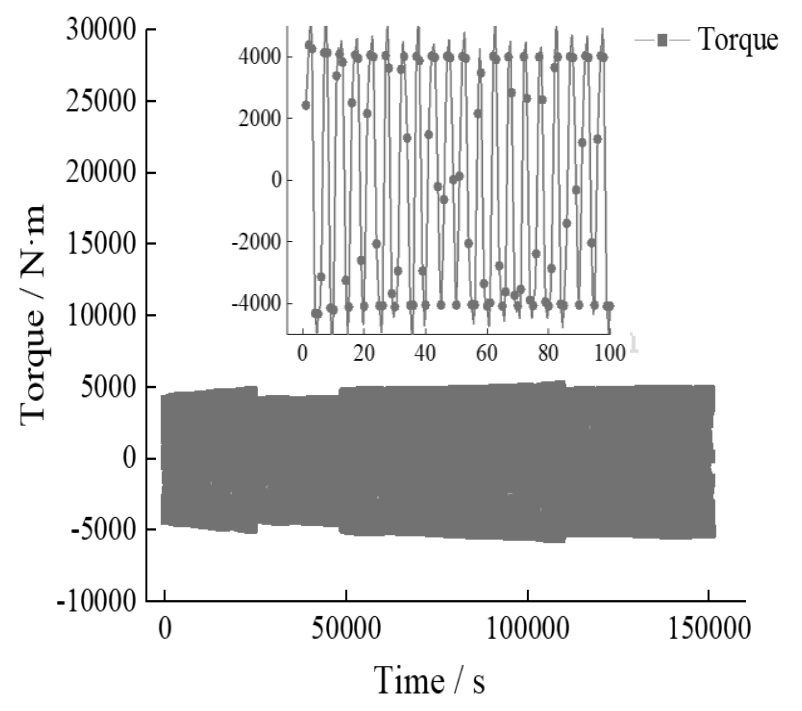

Fig. $10 \mathrm{ZH}$ bearings torque

According to Fig. 7, the appearance analysis of GE-90-ZH bearings before and after test is basically the same as that of GE-90-SKF bearings. There is no obvious fracture or breakage.

\section{Comparative analysis and research.}

Figs. 4, 5, 6, 8, 9 and 10 in the third part of the article will be analyzed comprehensively. According to the analysis of Fig. 4 and Fig. 8 of the bearing balance temperature relationship, the temperature of 3 sets of SKF bearings in 4 sets is basically the same in the early stage $(0-40 s)$, and temperature divergence occurs in the later stage. The temperature of bearing 2 and bearing 3 in Fig. 8 is exactly the same. At 140s, the temperature of the bearing 4 drops sharply and jumps irregularly. From the comparison relationship between bearing test torque and friction coefficient (Figs. 5 and 9), the torque and friction coefficient are proportional. Meanwhile, in the $\mathrm{ZH}$ bearings test, the relationship between torque and friction coefficient will occasionally jump. It is mainly caused by the instability of the bearing itself in the test. This also shows that SKF bearings is higher than $\mathrm{ZH}$ bearings in friction stability. Through 150000 tests, the torque comparison between the two brands of bearings (Fig. 6 and Fig. $10)$ is analyzed: the torque range is basically between 5000 N.m and 5000 N.m. From the microscopic curve analysis, the runout frequency and range are basically the same.

In the experiment, the grinding amount is also a very important parameter. As shown in Fig. 11.

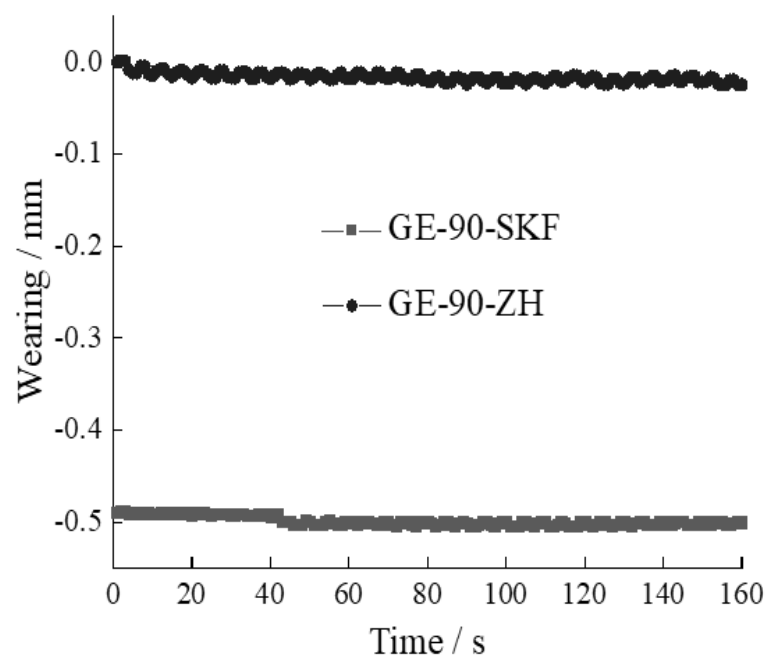

Fig. 11 Contrast relationship of wear amount

As shown in Fig. 11, there is a significant difference in that grin amount comparison. The wear amount of GE-90-ZH bearings are far lower than that of GE-90-SKF bearings, with a difference of about 0.5 $\mathrm{mm}$. This reflects that the production process and surface treatment methods of SKF bearings and $\mathrm{ZH}$ bearings are completely different at the limit temperature $\left(-160^{\circ} \mathrm{C}\right)$. From this point, it can be analyzed that the surface hardness of GE-90-ZH bearings are higher than that of GE-90-SKF bearings. 


\section{Conclusion}

In this paper, the high-speed rail bearings are tested at extreme low temperature $\left(-160^{\circ} \mathrm{C}\right)$. SKF and $\mathrm{ZH}$ brands and 4 sets bearings of each brand are selected as research carriers. The bearing temperature, environment temperature, torque change trend, the relationship between friction coefficient and torque ratio and wear amount of the whole bearing are analyzed. From the analysis results, it is found that the overall bearing temperature, environment temperature and torque change trends of SKF high-speed rail bearings and $\mathrm{ZH}$ high-speed rail bearings are basically consistent. The temperature changes of the two brands of bearings are between $-150^{\circ} \mathrm{C}$ and $-170^{\circ} \mathrm{C}$. And the friction coefficient is proportional to the ratio of torque. In the comparison of grinding amount, the wear amount of $\mathrm{ZH}$ bearings are far lower than that of SKF bearing, with a difference of about $0.5 \mathrm{~mm}$. This shows that the production process and surface treatment methods of the two bearings are completely different. Thereby affecting the service life of highspeed rail bearings.

\section{Acknowledgement}

This research was funded by the National Key Research \& Development Plan of China (No. 2020YFB2009602).

\section{References}

[1] FENG J, ZHANG G, YANG K. (2019). Study on Contact Stress Distribution of High-speed Railway Bearing. Metrology \& Measurement Technique, 046(005):53-58.

[2] Y HUANG, LIN J, LIU Z, W WU. (2019). A modified scale-space guiding variational mode decomposition for high-speed railway bearing fault diagnosis []. Journal of Sound and Vibration, 444:216-234.

[3] MA C., ZHANG G., WANG Y., ZHANG Z., REN Z. (2021). Effect of Non-metallic Inclusions on Subsurface Stress and Fatigue Life of
High-speed Railway Bearings [C]. IOP Conference

Series: Earth and Environmental Science, 632(5):052001 (12pp).

[4] GERGELY M., SOMOGYI S., BUZA G. (2013). Calculation of transformation sequences in quenched steel components to help predict internal stress distribution [J]. Metal Science Journal, 1(10):893-898.

[5] S.SJOSTROM. (1985). Interactions and constitutive models for calculating quenching stresses in steels [J]. Materials Science and Technology, 1(10):823-829

[6] R. SCHRODER. (1986). Untersuchungen zur Spannungs-und Eigenspannungsausbildung beim Abschrecken von Stahlzylindern [D]. Karlsrube: Karlsrube university.

[7] TUDOSE C., RUSU F., TUDOSE L. (2013). Influence of appropiate calculation of shaft support reactions on bearing life prediction[J]. Journal of Visualized Experiments, 4(79): e50772e50772.

[8] V., V., BUSHUEV, L., YA., GILOVOI, V., V., MOLODTSOV, F. (2019). Bearing Life in High-Speed Motorized Spindles with an HSK Interface []. Russian Engineering Research, 39(12):1073-1076.

[9] PEXA, M., ZDENĚK ALE, PAVL, J., JAKUB EDÍK. (2015). Impact of viscosity of motor oil on the wear of plain bearings [J]. Manufacturing Technology, 15(4), 670-674.

[10] H ISHIGURO. (2009). Introduction of Failure Case Example for Hydraulic Pump and Motor and New Bearing Life Calculation Method [J]. Journal of the Japan Fluid Power System Society, 40:234-239.

[11] STANCEKOVA, D., RUDAWSKA, A., J MRÁZIK, TURIAN, F. (2020). Comparision of the bearing rings deformation after heat treatment DJ. Manufacturing Technology, 20(5), 677683. 